\title{
PNEUMOCYSTIS JIROVECII PNEUMONIA: PREVALENCE IN HOSPITALISED PATIENTS, A STUDY CONDUCTED IN A TERTIARY CENTRE IN PUNJAB
}

\author{
Dilip Abraham¹, Aroma Oberoi², Eshani Dewan³, Vipin Sam Alexander 4 \\ ${ }_{1}^{1}$ Post Graduate Resident, Department of Microbiology, Christian Medical College and Hospital, Ludhiana. \\ 2 Professor \& HOD, Department of Microbiology, Christian Medical College and Hospital, Ludhiana. \\ ${ }_{3}^{3}$ Assistant Professor, Department of Microbiology, Christian Medical College and Hospital, Ludhiana. \\ ${ }_{4}^{4}$ Assistant Professor, Department of Microbiology, Christian Medical College and Hospital, Ludhiana.
}

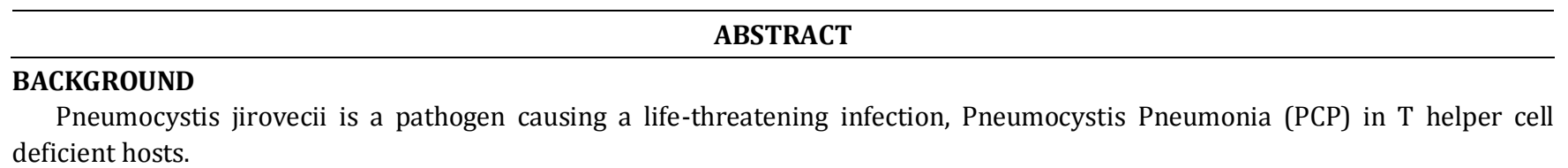
deficient hosts.

\section{METHODS}

A retrospective analysis was done from $6^{\text {th }}$ April 2012 to $11^{\text {th }}$ September 2015. The clinical data of the positive patients for PCP by Silver Methenamine Staining of the samples were collected. CD4 counts were done for the HIV positive patients.

\section{RESULTS}

A total of 486 samples were sent to the Microbiology Lab during this period for Silver Methenamine Staining. Among the patients, 13 (35.15\%) were diagnosed cases of HIV; 9 were Stage IV AIDS and all of these patients had CD4 counts less than $200 / \mu \mathrm{L}$

Fungal pneumonia was found to be a significant comorbidity in these patients and is of particular significance due to the diagnostic dilemma it can cause, since the radiological and physiological changes in both fungal and pneumocystis pneumonia are similar.

\section{CONCLUSION}

There should be a high index of suspicion for pneumocystis pneumonia in susceptible patients who show signs of atypical pneumonia and who do not respond to treatment with antibiotics or antifungals.

\section{KEYWORDS}

Pneumocystis Jirovecii, Pneumonia, Opportunistic Infections, CD4 Counts.

HOW TO CITE THIS ARTICLE: Abraham D, Oberoi A, Dewan E, et al. Pneumocystis jirovecii pneumonia: prevalence in hospitalised patients, a study conducted in a tertiary centre in Punjab. J. Evolution Med. Dent. Sci. 2016;5(32):1695-1698,

DOI: $10.14260 /$ jemds/2016/399

\section{INTRODUCTION}

Pneumocystis jirovecii is a pathogen causing a lifethreatening infection, Pneumocystis Pneumonia (PCP) in immunocompromised hosts. ${ }^{(1)}$

The earliest report of this organism was by Chagas in 1909.(2) Initially misidentified as a variant of Trypanosoma cruzi, it was later identified to be a whole other genus. Otto Jirovec identified this organism as causing interstitial pneumonia in infants in 1952.(3) and Frenkel later proposed the classification of the human pathogen as a different species, because of the varying antigenic properties and the lack of cross-infection from animals to man and vice versa.

The outbreak of pneumocystis pneumonia among malnourished children in an orphanage in Iran in the 1950's was well documented.(4-8) In the 1960's, it was a recognised pathogen in children with congenital $\mathrm{T}$ cell immunedeficiency.(9) but the incidence came down after the introduction of anti-pneumocystis medications.

Financial or Other, Competing Interest: None.

Submission 02-03-2016, Peer Review 28-03-2016,

Acceptance 04-04-2016, Published 19-04-2016.

Corresponding Author:

Dr. Aroma Oberoi,

Professor \& HOD,

Department of Microbiology,

Christian Medical College and Hospital,

Ludhiana, Punjab, India.

E-mail: draromaoberoi@yahoo.com

DOI: $10.14260 /$ jemds/2016/399
In the early 1980s, the increased incidence of pneumocystis pneumonia in a section of homosexual individuals in the United States led to the discovery of AIDS.(10)

Pneumocystis pneumonia is spread by airborne route and the rate of transmission is very high.(11) Studies have shown that immune-competent individuals can have the cysts colonised in their respiratory tract 24 hours after exposure to carriers and immune-competent people may act as carriers themselves even after latent infection has been cleared.(11-13) Studies show the presence of antibodies in children below the age of four and subsequent infections may be due to infection by other strains.(13)

Symptoms are vague and include mild cough, progressive dyspnoea $\left(\mathrm{PO}_{2}\right.$ less than $\left.65 \mathrm{mmHg}\right)$. Chest X-ray showing interstitial infiltrates and CT showing ground glass opacities.(14-16) This feature as well as physiological and pathological changes in the lung mimics that of mild fungal pneumonia.

In HIV negative patients the disease is more acute and more severe, progressing faster with a higher morbidity as it usually requires ICU admission.(17) while in HIV positive patients it shows a subacute course. The most common risk factors for developing PCP are solid organ tumours, haematological malignancies, inflammatory conditions and stem cell therapy. The incidence of pneumocystis pneumonia has been found to be associated with a $\mathrm{T}$ helper cell deficiency (CD4 counts) of less than $200 / \mu \mathrm{L}$. 
The median CD4 count in various studies was found to be $70 / \mu \mathrm{L}$ in such patients. The infection is rare above $200 / \mu \mathrm{L}$, but cases have been reported.(18)

The diagnosis of PCP should be made with alacrity due to the highly progressive nature of the disease. There have been a number of advances in the diagnosis of Pneumocystis infection including qrt-PCR and serological detection of $\beta$-D glucan- a cell wall component of the fungus. But these have disadvantages - PCR results have to be taken in the light of possible colonization and serological tests are non-specific. Therefore, microscopy remains the gold standard of diagnosis even though it is limited by its subjectivity and the need of an experienced microscopist.

\section{AIM}

We undertook this study to find out the prevalence of Pneumocystis pneumonia in patients in a tertiary care hospital in North India since studies done in this part of India were less.

\section{MATERIALS AND METHODS}

A retrospective analysis was done from $6^{\text {th }}$ April 2012 to $31^{\text {st }}$ December 2015; the clinical data of the positive patients for PCP by Silver methenamine staining of the sample were collected. The samples were sent to the Microbiology Lab from all departments and all wards including ICU's.

Silver methenamine staining was done on the samples and the samples were examined by an experienced microscopist.

The absolute $\mathrm{T}$ helper cell count (CD4 count) was estimated by flow cytometry using Alere PIMA cartridges. The cartridge works on the volumetric principle $-5 \mu \mathrm{L}$ of venous blood is drawn into the capillary receptacle. The cartridge has freeze-dried antibodies and during incubation it mixes with the blood and the CD4 cells are counted using inbuilt static camera and the reading is printed out.

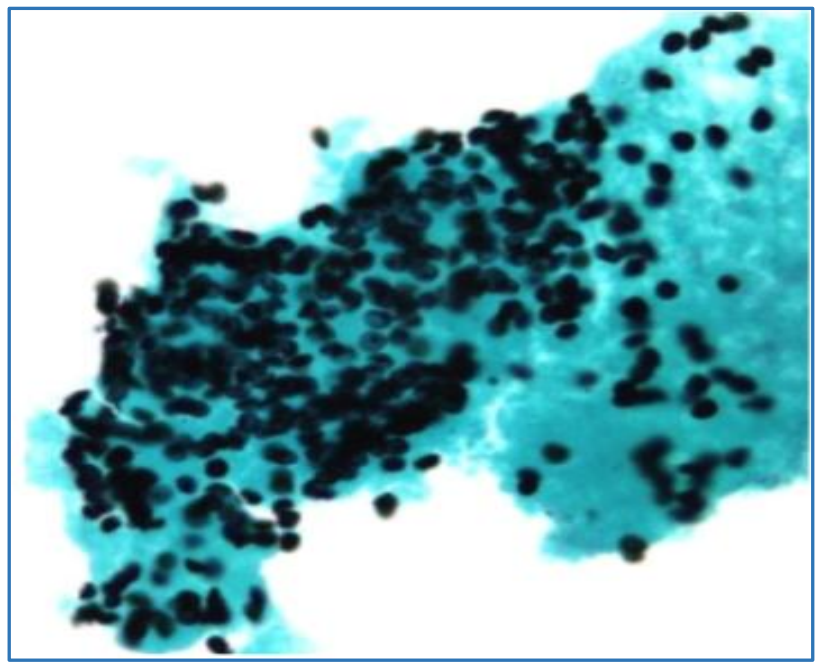

Fig. 1: Oocysts of Pneumocystis Jirovecii in a Sputum sample (Silver Methenamine Staining)

\section{RESULTS}

A total of 486 samples were sent to the Microbiology Lab during this period for Silver methenamine staining. Of these, 47 samples of 37 patients were found to be positive for oocysts of Pneumocystis jirovecii. Of the positive samples sent, 29 (61\%) were Sputum, 4 (9\%) were MiniBAL samples, 13 (28\%) were Bronchial secretions and 1 (2\%) was a BAL sample.

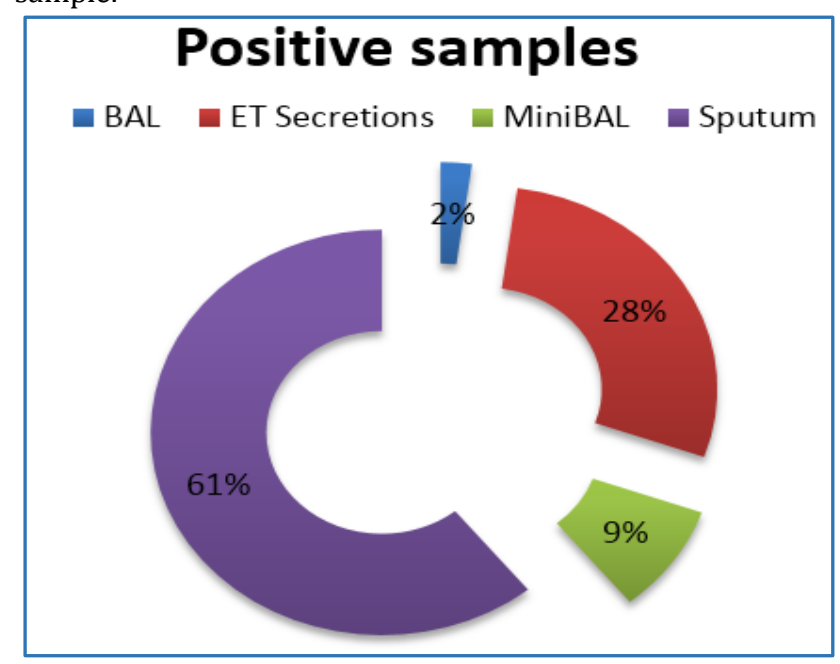

Fig. 2: Samples Positive for Pneumocystis Jirovecii

Among the patients, 13 (35.15\%) were diagnosed cases of HIV and 9 of these were Stage IV AIDS; all of these patients had CD4 counts less than $200 / \mu \mathrm{L}$.

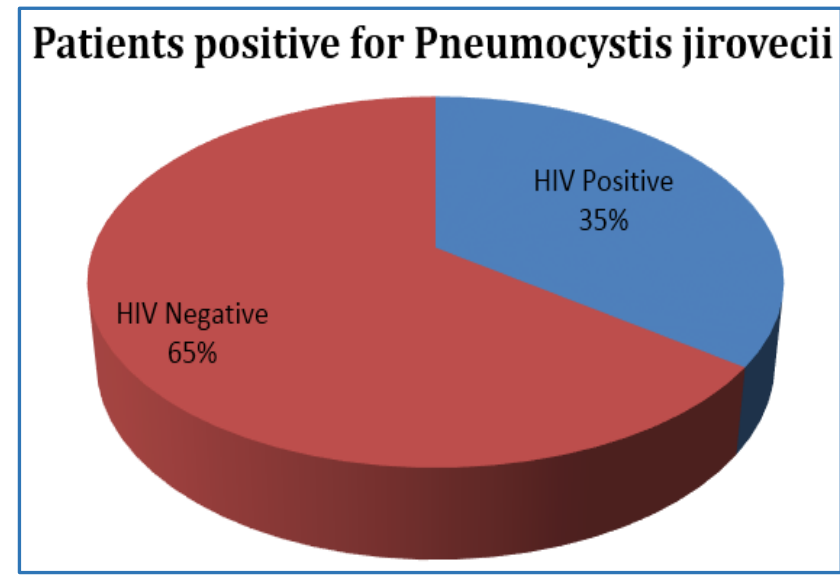

Fig. 3: HIV Status of Patients Positive for Pneumocystis Jirovecii

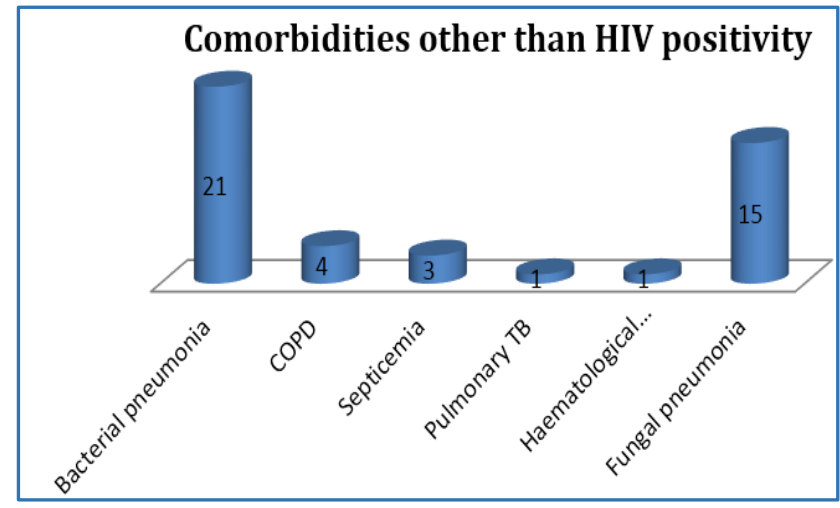

Fig. 4: Comorbidities of Positive Patients

Fungal pneumonia was found to be a significant comorbidity; 15 out of the 47 positive samples (31.9\%) were found to have growth on fungal culture, predominantly with 
Candida (In 14 of the cases) and one with Aspergillus. CD4 counts were done in 25 of the 37 cases.

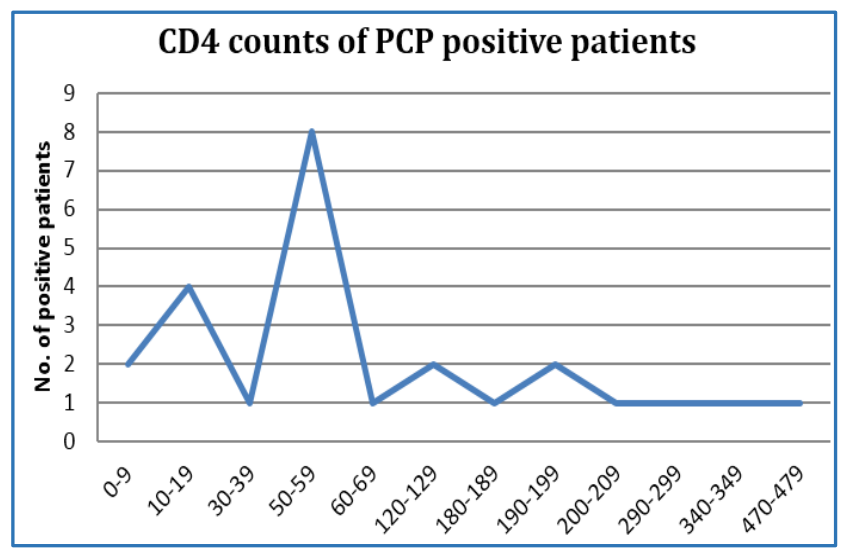

Fig. 5: CD4 counts of Patients with PCP

\section{DISCUSSION}

The incidence of PCP in patients with atypical pneumonia was found to be $9.6 \%$ in the general population. Approximately, a third of these $(35.15 \%)$ were diagnosed to be HIV positive. CD4 counts were done in all of the HIV positive patients, but only in 3 of the HIV negative patients.

The mean CD4 count was 110.8 and this is comparable to other studies (18), which have shown mean CD4 counts of 70 for PCP infection.

Discounting the 3 outliers who were HIV negative, the mean becomes 94.7 in our study. The graph (Fig. 5) shows bunching of positive points in the lower end and the maximum number of positive patients had counts of less than 70 or near it. This finding also correlates with other studies done.(18-19) Our finding also corresponds with studies done earlier in India in both the northern and southern regions. ${ }^{(20-}$ 21)

Concomitant bacterial (44.6\%) and fungal pneumonia (31.9\%) is a significant finding in our study. In such cases, the dilemma for the clinician is to decide whether to treat the positive Pneumocystis finding as an infection or merely colonization. Radiological examinations may be used to correlate these findings, but the non-specificity of Chest X-ray findings in atypical pneumonia and the fact that HRCT chest shows ground glass opacities for both fungal and pneumocystis pneumonia complicates this further.

\section{CONCLUSION}

There should be close collaboration between the clinician and the microbiologist regarding these high risk patients. Any case of pneumonia not responding to antibiotics or antifungals should be suspected of atypical infections like PCP and treated aggressively due to the fatal course of the illness, especially in HIV negative patients.

\section{REFERENCES}

1. Stringer JR, Beard CB, Miller RF, et al. A new name (Pneumocystis jiroveci) for pneumocystis from humans. Emerging Infectious Diseases 2002;8(9):891-6.
2. Chagas C. Neuetrypanosomen. Vorläufige Mitteilung Arch Schiff Tropenhyg 1909;13:120-2.

3. Vanek J, Jírovec 0, Lukes J. Interstitial plasma cell pneumonia in infants. Ann Paediatrici 1953;180(1):121.

4. Frenkel JK. Pneumocystis jiroveci n. sp. from man: morphology, physiology, and immunology in relation to pathology. Natl Cancer Inst Monogr 1976;43:13-30.

5. Dutz W. Pneumocystis carinii pneumonia. Pathology Annual 1970;5:309-41.

6. Dutz W, Post $\mathrm{C}$, Vessal $\mathrm{K}$, et al. Endemic infantile pneumocystis carinii infection: the shiraz study. Natl Cancer Inst Monogr 1976;43:31-40.

7. Dutz W. Autopsy pathology and disease patterns in shiraz, Iran, 1960-1974. IARC Sci Publ 1991;112:26981.

8. Sokulska M, Kicia M, Wesołowska M, et al. Pneumocystis jirovecii-from a commensal to pathogen: clinical and diagnostic review. Parasitology Research 2015;114(10):3577-85

9. Walzer PD, Schultz MG, Western KA, et al. Pneumocystis carinii pneumonia and primary immune deficiency diseases. Natl Cancer Inst Monogr 1976;43:65-74.

10. Gottlieb MS. Pneumocystis pneumonia-los angeles 1981. Am J Public Health 2006;96(6):980-1. discussion 982-3.

11. Dumoulin A, Mazars E, Seguy N, et al. Transmission of pneumocystis carinii disease from immunocompetent contacts of infected hosts to susceptible hosts. Eur J Clin Microbiol Infect Dis 2000;19(9):671-8. Available from:http://www.ncbi.nlm.nih.gov/pubmed/11057500 $\backslash n P M: 11057500$.

12. Gigliotti F, Harmsen AG, Wright TW. Characterization of transmission of pneumocystis carinii f spmuris through immunocompetent $\mathrm{BALB} / \mathrm{c}$ mice. Infect Immun 2003;71(7):3852-6.

13. Piffer L, Hughes WT, Stagno S, et al. Pneumocystis carinii infection: evidence for high prevalence in normal and immunosuppressed children. Pediatrics 1978;61(1):3541.

14. Phair J, Munoz A, Detels R, et al. The risk of pneumocystis carinii pneumonia among men infected with human immunodeficiency virus type 1 . N EngJ Med 1990;322:161-5.

15. Barry SM, Johnson MA. Pneumocystis carinii pneumonia: a review of current issues in diagnosis and management. HIV Med 2001;2(2):123-32.

16. Vogel MN, Vatlach M, Weissgerber P, et al. HRCT-features of pneumocystis jiroveci pneumonia and their evolution before and after treatment in non-HIV immunocompromised patients. Eur J Radiol 2012;81(6):1315-20.

17. Roblot F, Godet C, Le Moal G, et al. Analysis of underlying diseases and prognosis factors associated with pneumocystis carinii pneumonia in immunecompromised HIV-negative patients. Eur J Clin Microbiol Infect Dis 2002;21(7):523-31. 
18. Crowe SM, Carlin JB, Stewart KI, et al. Predictive value of CD4 lymphocyte number for the development of opportunistic infections and malignancies in HIVinfected persons. J Acquir Immune Defic Syndr 1991;4(8):770-6. Available from: http://www.embase.com/search/results?subaction=vie wrecord\&from=export\&id=L21251077\nhttp://sfx.libr ary.uu.nl/utrecht?sid=EMBASE\&issn=08949255\&id=doi :\&atitle=Predictive+value + of + CD $4+$ lymphocyte + numbe $\mathrm{r}+$ for+the+development+of+opportunistic+infections $+\mathrm{a}$ nd+malig.
19. Stansell JD, Osmond DH, Charlebois E, et al. Predictors of pneumocystis carinii pneumonia in HIV-infected persons pulmonary complications of HIV infection study group. Am J Respir Crit Care Med 1997;155(1):60-6. Available

from:http://www.ncbi.nlm.nih.gov/pubmed/9001290.

20. Kaur R, Wadhwa A, Bhalla P, et al. Pneumocystis pneumonia in HIV patients: a diagnostic challenge till date. Med Mycol 2015;53(6):587-92.

21. Shahapur PR, Bidri RC. Recent trends in the spectrum of opportunistic infections in human immunodeficiency virus infected individuals on antiretroviral therapy in south India. J Nat Sci Biol Med 2014;5(2):392-6. 